Proc. Estonian Acad. Sci. Eng., 2002, 8, 2, 121-133

\title{
Discrete and continuous modelling of suspension bridges
}

\author{
Valdek Kulbach, Siim Idnurm, and Juhan Idnurm \\ Department of Structural Design, Tallinn Technical University, Ehitajate tee 5, 19086 Tallinn, \\ Estonia; \{vkulbach, sidnurm\}@edu.ttu.ee \\ Received 26 February 2002, in revised form 1 April 2002

\begin{abstract}
In the calculation of suspension bridges, the main problem is the geometrically nonlinear behaviour of the cable. Linear methods of analysis are suitable only for very small spans. A geometrically non-linear continuous model is especially useful for classical loading cases as for the uniformly distributed load on the whole or half span. However, traffic generates both concentrated and uniformly distributed loads. The discrete model of a suspension bridge allows one to apply all kinds of loads, such as the distributed and the concentrated ones. In this paper, application of both discrete and continuous models for the calculation of the suspension bridges is considered. Linear elastic strain-stress dependence of the material and absence of the inclination of hangers is assumed. Hanger elongation may be taken into account. Some comparative numerical examples are presented.
\end{abstract}

Key words: suspension bridge, cable systems, continuous modelling, discrete modelling, geometric non-linearity, girder-stiffened structures.

\section{INTRODUCTION}

Classical treatment of suspension bridges is presented in $\left[{ }^{1,2}\right]$. A generalized method of continuous modelling of different prestressed cable structures was proposed in $\left[{ }^{3-5}\right]$. It includes plane structures $\left[{ }^{3,5}\right]$ and spatial networks $\left[{ }^{4}\right]$ and proceeds from geometrically non-linear equilibrium conditions and equations of deformation compatibility. A peculiarity of this method is immediate inserting of displacements of cable supports into the generalized equations of deformation compatibility.

Recent publications in the field of suspension bridges consider mainly the wind-induced dynamic processes and specific problems of the design of bridge elements $\left[{ }^{6}\right]$. A thorough review of literature in this field is given in the handbook $\left.{ }^{7}\right]$. However, in $\left[^{7}\right]$ only linear models have been considered. More recent 
papers on suspension bridges consider application of the standard finite element method $\left[{ }^{8,9}\right]$.

In this paper the analysis of the suspension bridges is carried out using nonlinear equilibrium conditions and generalized equations of deformation compatibility, taking into account the actual boundary conditions. Discrete and continuous calculation models are used in parallel.

\section{DISCRETE MODEL FOR AN ELASTIC CABLE}

\subsection{Initial form of the cable}

Under uniformly distributed load a cable takes parabolic form. In reality the cable is loaded by concentrated forces. Therefore it takes the form of a string polygon. The cable may be regarded as a geometrically non-linear rod without bending stiffness. The nodes of the polygon are on a parabola only if applied forces are equal and equidistant. The initial state of equilibrium of a cable, loaded by vertical concentrated loads, is shown in Fig. 1.

From the equilibrium considerations we may write for every node

$$
H_{0}\left(\frac{z_{i-1}-z_{i}}{a_{i-1}}+\frac{z_{i+1}-z_{i}}{a_{i}}\right)+F_{0, i}=0,
$$

where $H_{0}$ is the initial horizontal force in the cable, $z_{i-1}, z_{i}$, and $z_{i+1}$ are the initial vertical coordinates of the nodes, and $F_{0, i}$ is the initial external force at the node $i$.

From Eq. (1) we have

$$
z_{i}=\frac{1}{1+\frac{a_{i}}{a_{i-1}}}\left(z_{i-1} \frac{a_{i}}{a_{i-1}}+z_{i+1}+\frac{F_{0, i} a_{i}}{H_{0}}\right) .
$$

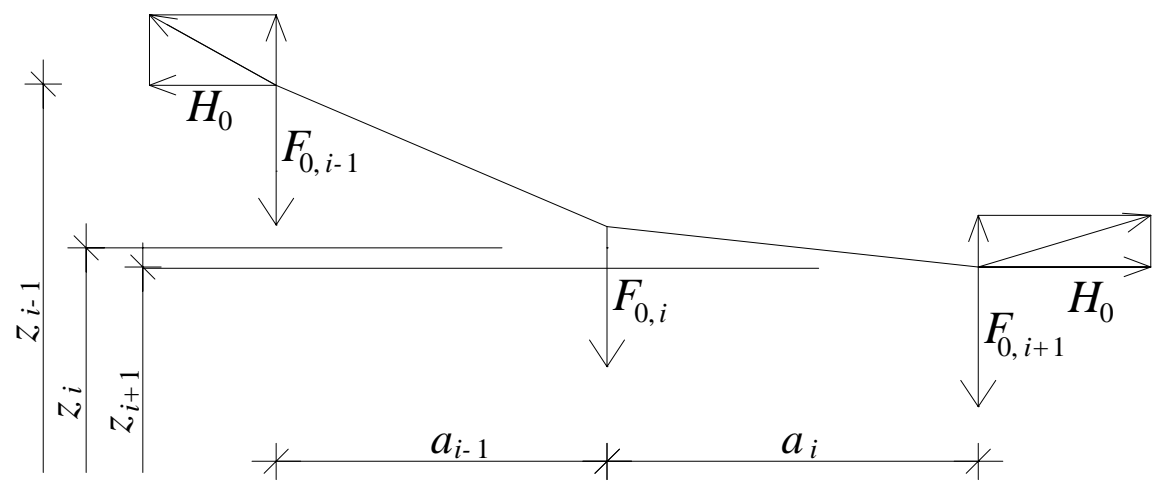

Fig. 1. Discrete scheme of a cable element in the state of equilibrium. 
In case of equidistant vertical loads, Eq. (2) takes the form

$$
z_{i}=\frac{1}{2}\left(z_{i-1}+z_{i+1}+\frac{F_{0, i} a}{H_{0}}\right) .
$$

Equations (2) and (3) give the ordinates of the string polygon if the horizontal force $H_{0}$ is known. When the supporting points of the cable are on the same level $\left(z_{1}=z_{n+1}\right)$, then

$$
H_{0}=V_{0} \frac{a_{0}}{z_{2}-z_{1}}=\frac{a_{0} \sum_{i=1}^{n} F_{0, i}\left(l-x_{i}\right)}{l\left(z_{2}-z_{1}\right)},
$$

where

$$
V_{0}=\frac{\sum_{i=1}^{n} F_{0, i}\left(l-x_{i}\right)}{l}
$$

is the vertical reaction from the initial loads $F_{0, i}$ and $l$ is the length of the horizontal projection of the cable.

For a cable with supporting nodes on different levels we have

$$
H_{0}=\frac{a_{0} \sum_{i=1}^{n} F_{0, i}\left(l-x_{i}\right)}{l\left(z_{2}-z_{1}\right)-a_{0}\left(z_{1}-z_{n+1}\right)} .
$$

The initial form of the string polygon is described by three coordinates $z_{1}, z_{2}$, and $z_{n+1}$.

\subsection{The loaded cable}

By the action of the additional loads $\Delta F_{i}$ (Fig. 2), the equilibrium equation for the node $i$ is expressed as

$$
H\left(\frac{z_{i-1}-z_{i}}{a_{i-1}}+\frac{z_{i+1}-z_{i}}{a_{i}}+\frac{w_{i-1}-w_{i}}{a_{i-1}}+\frac{w_{i+1}-w_{i}}{a_{i}}\right)+F_{i}=0,
$$

where $w_{i-1}, w_{i}$, and $w_{i+1}$ are vertical displacements, $H$ is the cable force from temporary and initial loads, and $F_{i}=F_{0, i}+\Delta F_{i}$.

From Eq. (6), the vertical displacement can be expressed as

$$
w_{i}=\frac{1}{1+\frac{a_{i}}{a_{i-1}}}\left[w_{i-1} \frac{a_{i}}{a_{i-1}}+w_{i+1}+\frac{a_{i}}{a_{i-1}}\left(z_{i-1}-z_{i}\right)+\left(z_{i+1}-z_{i}\right)+\frac{F_{i} a_{i}}{H}\right] .
$$




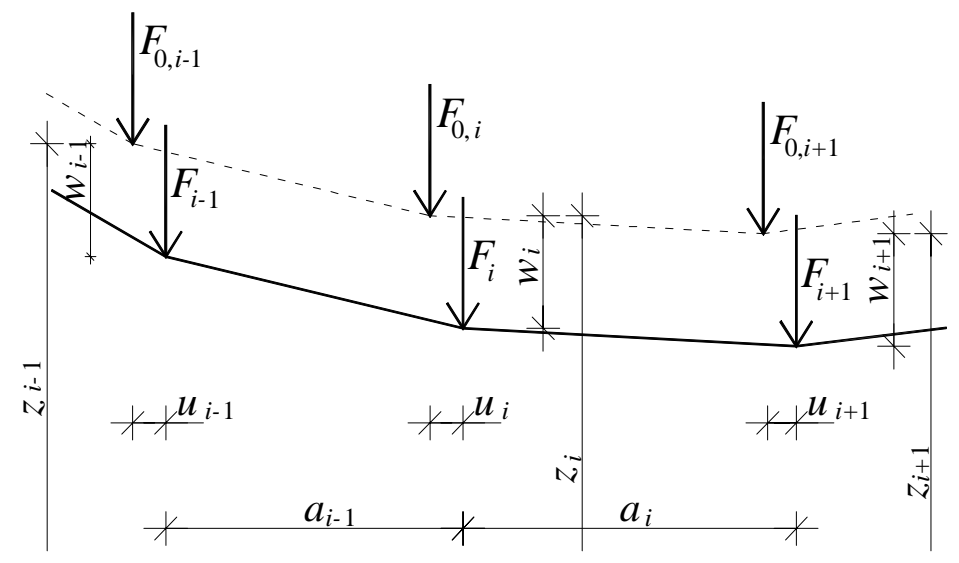

Fig. 2. Deformation of the cable under additional load.

There are two unknown parameters in Eq. (7), $w_{i}$ and $H$. Thus we need an additional equation for calculating them. For this purpose we use the equality of the relative elongation of the cable $\varepsilon_{i}\left[{ }^{3}\right]$ expressed through node displacements

$$
\varepsilon_{i}=\frac{1}{1+\left(\frac{z_{i+1}-z_{i}}{a_{i}}\right)^{2}}\left[\frac{u_{i+1}-u_{i}}{a_{i}}+\frac{w_{i+1}-w_{i}}{a_{i}}\left(\frac{z_{i+1}-z_{i}}{a_{i}}+\frac{w_{i+1}-w_{i}}{2 a_{i}}\right)\right] \text {, }
$$

and from the condition of linear deformation

$$
\varepsilon_{i}=\frac{H-H_{0}}{E A} \sqrt{1+\left(\frac{z_{i+1}-z_{i}}{a_{i}}\right)^{2}},
$$

where $E A$ is the stiffness of the cable in tension ( $E$-elasticity modulus, $A-$ cross-section of the cable).

Taking into account Eqs. (8) and (9), this condition may be presented as

$$
\frac{u_{i+1}-u_{i}}{a_{i}}=\frac{H-H_{0}}{E A}\left[1+\left(\frac{z_{i+1}-z_{i}}{a_{i}}\right)^{2}\right]^{3 / 2}-\frac{w_{i+1}-w_{i}}{a_{i}}\left(\frac{z_{i+1}-z_{i}}{a_{i}}+\frac{w_{i+1}-w_{i}}{2 a_{i}}\right) \text {. }
$$

Horizontal displacements $u_{i}$ of the internal nodes may be eliminated by summation of the equations of deformation compatibility (10). Then, since

$$
\sum_{i=0}^{n}\left(u_{i+1}-u_{i}\right)=u_{n+1}-u_{1}
$$

we may write Eq. (10) in the form 


$$
\begin{array}{r}
\frac{H-H_{0}}{E A}\left\{\sum_{i=1}^{n} a_{i}\left[1+\left(\frac{z_{i+1}-z_{i}}{a_{i}}\right)^{2}\right]^{\frac{3}{2}}-\frac{E A}{H-H_{0}}\left(u_{n+1}-u_{1}\right)\right\} \\
=\sum_{i=1}^{n}\left(w_{i+1}-w_{i}\right)\left(\frac{z_{i+1}-z_{i}}{a_{i}}+\frac{w_{i+1}-w_{i}}{2 a_{i}}\right),
\end{array}
$$

where $u_{1}$ and $u_{n+1}$ are displacements of the supports.

Solution of the system of non-linear equations (6) and (12) permits calculation of $H$ and all the displacements $w_{i}$ from the initial cable form and boundary conditions for $u_{1}$ and $u_{n+1}$.

\subsection{Discrete model of an elastic cable with the stiffening girder}

The scheme of a girder-stiffened suspension bridge calculation model is presented in Fig. 3. The initial vertical load $F_{0, i}$ is fully balanced by the cable and prestresses it. The force $H_{0}$ can be calculated from Eqs. (4) or (5). Part of the additional load $P$ is balanced by the cable and the rest of it by the stiffening girder. The equation that describes the deflection of the girder can be written as

$$
\begin{aligned}
E_{\mathrm{b}} I_{\mathrm{b}} w(x)=E_{\mathrm{b}} I_{\mathrm{b}} w_{1} & +E_{\mathrm{b}} I_{\mathrm{b}} \varphi_{1} x-\sum_{j=1}^{m} F_{j} \frac{\left(x-a_{j}\right)^{2}}{2} \cdot \mathcal{H}\left(x-a_{j}\right) \\
& +\sum_{k=1}^{s} F_{k} \frac{\left(x-b_{k}\right)^{3}}{6} \cdot \mathcal{H}\left(x-b_{k}\right)+\sum_{l=1}^{t} p_{l} \frac{\left(x-c_{l}\right)^{4}}{24} \cdot \mathcal{H}\left(x-c_{l}\right) \\
& -\sum_{l=1}^{t} p_{l} \frac{\left(x-d_{l}\right)^{4}}{24} \cdot \mathcal{H}\left(x-d_{l}\right),
\end{aligned}
$$

where $E_{\mathrm{b}} I_{\mathrm{b}}$ is the rigidity of the stiffening girder in bending, $w_{1}$ is the vertical displacement, and $\varphi_{1}$ is the angle of rotation of the first cross section of the girder, $a_{\mathrm{j}}, b_{k}, c_{l}$, and $d_{l}$ are the coordinates of the points of application of the forces, and $\mathcal{H}(x)$ is the Heaviside function.

Equation (13) can be used for calculating the deflection from the sum of applied external concentrated moments, forces $F_{k}$, and from the uniformly distributed load $p_{l}$.

In the case of vertical pylons, the horizontal displacements of the supporting nodes of the anchor cable may be presented as

$$
u_{1}=u_{n+1}=\frac{\left(H-H_{0}\right) 2 b}{E A \cos ^{3} \alpha},
$$

where $2 b$ is the span and $\alpha$ is the angle of inclination of the anchor cable. 


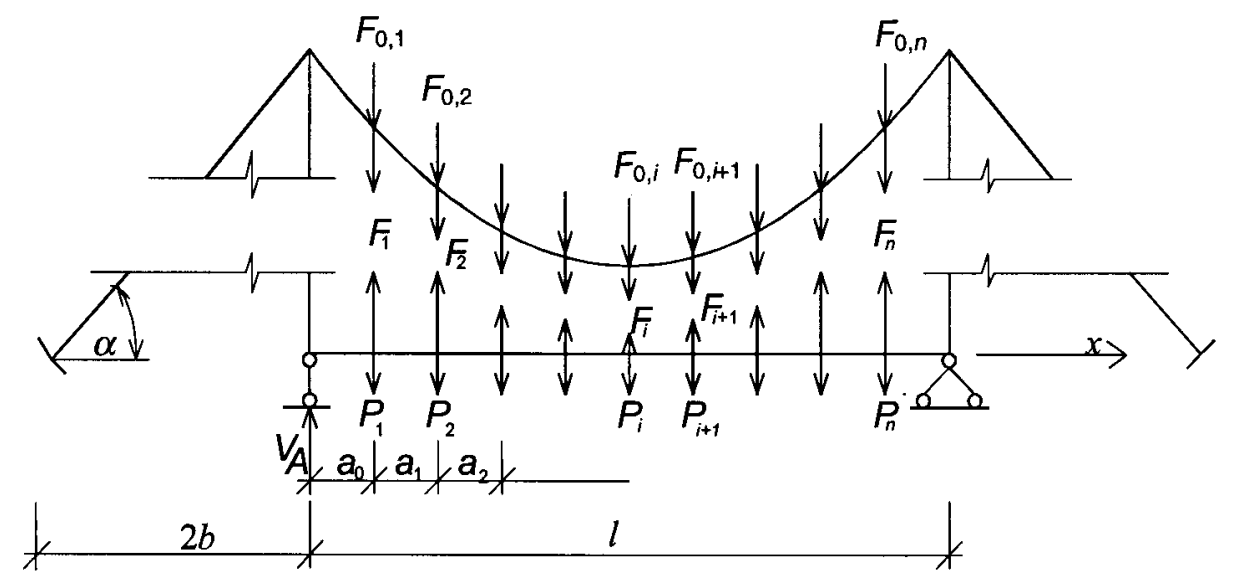

Fig. 3. A suspension bridge model with vertical pylons and straight anchor cables.

Using Eq. (13), we can write for every hanger joint and the end cross-section of the girder

$$
\begin{aligned}
w_{m}=w_{1}+\varphi_{1} x_{m} & +\sum_{i=2}^{m-1} F_{i} \frac{\left(x_{m}-x_{i}\right)^{3}}{6 E_{\mathrm{b}} I_{\mathrm{b}}}+V_{\mathrm{A}} \frac{x_{m}^{3}}{6 E_{\mathrm{b}} I_{\mathrm{b}}}-\sum_{k=1}^{s} F_{k} \frac{\left(x-b_{k}\right)^{3}}{6} \cdot \mathcal{H}\left(x-b_{k}\right) \\
& +\sum_{l=1}^{t} \frac{\left(x-c_{l}\right)^{4}}{24} \cdot \mathcal{F}\left(x-c_{l}\right)-\sum_{l=1}^{t} \frac{\left(x-d_{l}\right)^{4}}{24} \cdot \mathcal{H}\left(x-d_{l}\right),
\end{aligned}
$$

where $F_{i}$ is the internal force in the hangers and $V_{\mathrm{A}}$ is the vertical support reaction.

Now we have $n$ linear equations for calculating $F_{i}$, but there are $n+2$ unknown parameters: $F_{1}, F_{2} \ldots F_{n}, F_{\mathrm{A}}$, and $\varphi_{1}$. An additional equation can be written, using the moment equilibrium condition upon the end cross-section of the girder, as follows:

$$
\sum_{i=2}^{n} F_{i}\left(l-x_{i}\right)+V_{\mathrm{A}} l+M=0
$$

where $M$ is the moment of the external forces at the end of the girder. Thus with the system of linear equations (15) and (16) it is possible to calculate the internal forces $F_{i}$ in the hangers if the displacements $w_{i}$ are known.

Now we can construct an iteration process for calculating the displacements $w_{i}$, the cable force $H$, and the internal forces in hangers $F_{i}$ as follows:

1) calculation of the prestressing (initial) forces in the cable from Eqs. (2)-(6); the initial load $F_{0}$ consists of the weight of the cable and of the part of the weight of the deck structure of the bridge;

2) estimation of the initial displacements of the stiffening girder $w_{i, 0}$; 
3) from the system of linear equations (15) and (16), calculation of the internal forces $F_{i}$ under action of the additional load $P_{i}$;

4) calculation of the vertical displacements of the cable from Eqs. (7), (12), and (14);

5) comparison of the vertical displacements of the stiffening girder and the cable; if they differ more than permissible then new stiffening girder displacements are to be calculated and the process is to be repeated starting from point 3 until the whole process converges;

6) the calculation process is finished when the vertical displacements of the cable and the stiffening girder are equal; then the final values of the cable force $H$, of the internal forces of hangers $F_{i}$, and the vertical displacements of the cable and of the girder are determined. The internal forces in the stiffening girder can be calculated as in a simple beam.

\section{CONTINUOUS MODEL}

\subsection{Basic equations}

Equilibrium condition for a continuous girder-stiffened cable structure may be presented as follows $\left[{ }^{3}\right]$

$$
\frac{E_{\mathrm{b}} I_{\mathrm{b}} \mathrm{d}^{4} w}{\mathrm{~d} x^{4}}-H\left(\frac{\mathrm{d}^{2} z}{\mathrm{~d} x^{2}}+\frac{\mathrm{d}^{2} w}{\mathrm{~d} x^{2}}\right)+p=0,
$$

where $w$ is the deflection function and $p$ is the vertical distributed load.

The initial form of the cable is usually a parabola (Fig. 4)

$$
z=f \frac{x^{2}}{a^{2}},
$$

where $a$ is the half-span and $f$ the sag of the cable. When assembling the stiffening girder by successive lifting and suspending its mounting units to the cable and connecting them to each other, the initial load of the cable $p_{0}$ consists of the weight of the cable and the girder together. Corresponding horizontal force of the cable is

$$
H_{0}=\frac{p_{0} a^{2}}{2 f} .
$$

The compatibility condition of the relative elongation of the cable may be expressed as a condition of equality of geometrical and elastic deformations

$$
\frac{\mathrm{d} u}{\mathrm{~d} x}+\frac{\mathrm{d} w}{\mathrm{~d} x}\left(\frac{\mathrm{d} z}{\mathrm{~d} x}+\frac{\mathrm{d} w}{2 \mathrm{~d} x}\right)=\frac{\left(H-H_{0}\right)}{E A}\left[1+\left(\frac{\mathrm{d} z}{\mathrm{~d} x}\right)^{2}\right]^{\frac{3}{2}},
$$




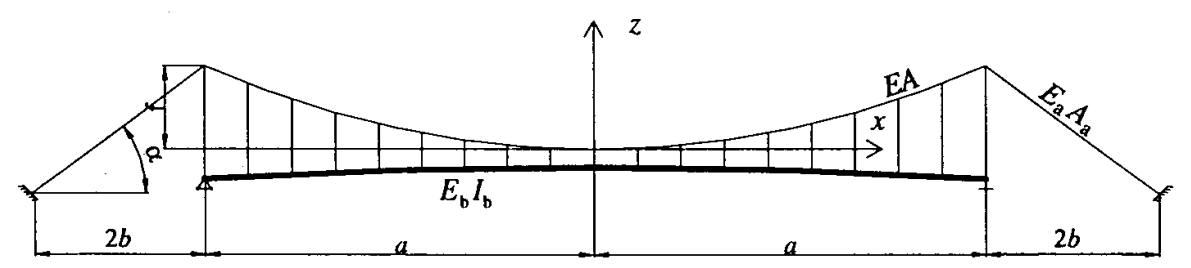

Fig. 4. Continuous model of a suspension bridge with straight anchor cables.

where $E A$ is rigity of the cable in tension and $u$ is horizontal displacement. To eliminate the displacement $u$, we have to integrate Eq. (20) over the cable span. The unknowns $w$ and $H$ are determined by Eqs. (17) and (20).

\subsection{The structure with straight anchor cables}

For the displacement of the cable support under action of the anchor cable, we may write

$$
\int_{0}^{a} \frac{\mathrm{d} u}{\mathrm{~d} x} \mathrm{~d} x=\left(H-H_{0}\right) \frac{2 b}{E_{\mathrm{a}} A_{\mathrm{a}} \cos ^{3} \alpha} .
$$

Using boundary conditions, after integration of Eqs. (17) and (20) we obtain exact expression for $\left(E_{\mathrm{b}} I_{\mathrm{b}} / H\right)^{1 / 2}$ in a complicated transcendental form. On the other hand, we may approximate the cable deflection by a trigonometric function

$$
w=-w_{0} \frac{\cos \pi x}{2 a},
$$

where $w_{0}$ is the deflection of the central point of the cable. Using Eqs. (17) and (20) we obtain with Galjorkin procedures, after some simplifications, a cubic equation for the relative deflection $\zeta_{0}=w_{0} / f$

$$
\zeta_{0}^{3}+3 \zeta_{0}^{2}+\left(2+\rho+p_{0}^{*}\right) \zeta_{0}=p^{*}
$$

and for the cable force

$$
H=H_{0}+\Phi \zeta_{0}\left(2+\zeta_{0}\right)
$$

Here $p_{0}^{*}=H_{0} / \Phi$ and $p^{*}=\rho a^{2} /(2 f \Phi)$ are parameters of the initial and additional loads, respectively; $\rho=4 E_{\mathrm{b}} I_{\mathrm{b}}(1+\kappa+\vartheta) /\left(E A f^{2}\right)$ is parameter of rigidity of the stiffening girder, $\Phi=2 E A f^{2} /\left[3 a^{2}(1+\kappa+\vartheta)\right]$ is the rigidity factor of the cable, $\kappa=2 f^{2} / a^{2}+1,2 f^{4} / a^{4}$ is a geometrical factor and $\vartheta=2 E A b /\left(E_{\mathrm{a}} A_{\mathrm{a}} a \cos ^{3} \alpha\right)$ is the factor of deformatibility of the anchor cable.

For the case of half-span loading of the bridge by a live load, it is useful to divide the total load into symmetrical $\left(p_{\mathrm{s}}\right)$ and antisymmetrical $\left(p_{\mathrm{u}}\right)$ parts and to make the analysis in two steps. When calculating displacements and inner 
forces for the antisymmetrical load, new geometrical and statical parameters are to be used. The deflection function for the antisymmetrical load is approximated as

$$
w=-w_{1} \sin \frac{\pi x}{a} .
$$

The deflection parameter of the structure may be obtained from the equation

$$
\zeta_{1}^{3}+\left(\rho_{1}+p_{\mathrm{s}}^{*}\right) \zeta_{1}=p_{\mathrm{u}}^{*},
$$

where

$$
\begin{gathered}
\zeta_{1}=w_{1} / f_{1}, \quad f_{1}=f\left(1+\zeta_{0}\right), \quad \rho_{1}=\rho /\left(1+\zeta_{0}\right)^{3}, \\
p_{0 \mathrm{~s}}^{*}=\frac{\left(p_{0}+p_{\mathrm{s}}\right) a^{2}}{2 f_{1} \Phi_{1}}, \quad p_{\mathrm{u}}^{*}=\frac{p_{\mathrm{u}} a^{2}}{8 f_{1} \Phi_{1}}, \quad \Phi_{1}=\frac{15 E A f_{1}^{2}}{4 a^{2}(1+\kappa+\vartheta)} .
\end{gathered}
$$

\subsection{Suspension bridge with loaded anchor cables}

In case of a symmetrical bridge with loaded anchor cables (Fig. 5.), the condition of equilibrium (17) and the equation of deformation compatibility (20) are to be applied to the middle span and to anchor spans as well. The boundary conditions for the connecting point of cables consist of the equality of horizontal cable forces both before and after loading and of the equality of horizontal displacements. For horizontal cable forces before and after additional loading we may write

$$
\begin{gathered}
\frac{p_{0} a^{2}}{2 f}=\frac{p_{01} b^{2}}{2 f_{1}}, \\
\frac{\left(p_{0}+p\right) a^{2}}{2 f\left(1+\zeta_{0}\right)}=\frac{\left(p_{01}+p_{1}\right) b^{2}}{2 f_{1}\left(1+\zeta_{1}\right)},
\end{gathered}
$$

where index 1 indicates the loaded anchor cable and $\zeta_{1}=w_{1} / f_{1}$ is relative deflection parameter of it. From Eq. (27) we obtain

$$
f_{1}=f \frac{p_{01} b^{2}}{p_{0} a^{2}} \text {. }
$$

Equation (28) brings us to the equality

$$
1+\zeta_{1}=\tau\left(1+\zeta_{0}\right) .
$$

Now we may write the condition of equality of displacements of the upper end of the pylon, determined from the middle span and from the side span of the 


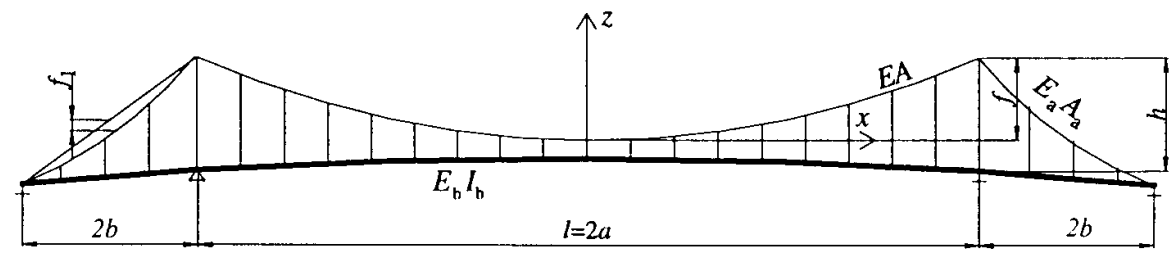

Fig. 5. Suspension bridge with loaded anchor cables.

cable, in the form which enables us to calculate relative displacement of the cable in the middle span of the structure

$$
\begin{gathered}
\left(1+\psi \tau^{2}\right) \zeta_{0}^{3}+3\left(1-\psi \tau^{2}\right) \zeta_{0}^{2}+\left[2+\psi\left(1-3 \tau^{2}\right)+\left(p_{0}^{*}+\rho\right)-\psi\left(p_{01}^{*}+\rho_{1}\right)\right] \zeta_{0} \\
=p^{*}+\frac{\psi}{\tau} p_{1}^{*}-\psi\left(1-\frac{1}{\tau}\right)\left(p_{01}^{* *}+\rho_{1}\right)+\psi\left(1-\tau^{2}\right)
\end{gathered}
$$

where

$$
\begin{gathered}
\psi=2 a f_{1}^{2} /\left(b f^{2}\right), \quad \tau=\left(p_{01}+p_{1}\right) b^{2} f /\left[\left(p_{0}+p\right) a^{2} f_{1}\right], \quad p_{01}^{*}=H_{0} / \Phi_{1}, \\
p_{1}^{*}=p_{1} a^{2} /\left(2 f_{1} \Phi_{1}\right), \quad \Phi_{1}=2 E a f_{1}^{2} /\left[3 b^{2}\left(1+\kappa_{1}\right)\right], \\
\kappa_{1}=2 f_{1}^{2} / b^{2}+3 h^{2} /\left(8 b^{2}\right)+3 h_{1} f_{1} / b^{2}+3 h_{1}^{3} f_{1} /\left(2 b^{4}\right)+3 h^{4} /\left(128 b^{4}\right) .
\end{gathered}
$$

After determination of the relative deflection $\zeta_{0}$, we can calculate the corresponding deflection of the anchor span $\zeta_{1}$ from Eq. (30). Horizontal cable force may be calculated as

$$
H=H_{0}+\Phi \zeta_{0}\left(2+\zeta_{0}\right) .
$$

\section{NUMERICAL EXAMPLES}

Let us consider suspension bridges with the parameters, used for provisional design of the bridge from the Estonian mainland to the Saaremaa Island (Table 1).

Table 1. Parameters of the suspension bridges

Span, $m$

Sag of the cable, $m$

$\begin{array}{ccccc}600 & 780 & 960 & 1080 & 1200 \\ 75 & 97.5 & 120 & 135 & 150 \\ 250 & 325 & 400 & 450 & 500 \\ 1269 & 2488 & 2964 & 4524 & 5896 \\ 210 & 210 & 210 & 210 & 210 \\ 768 & 1092 & 1458 & 1738 & 2008 \\ 170 & 170 & 170 & 170 & 170 \\ 30.4 & 38.2 & 43.3 & 50.0 & 54.8 \\ 14.4 & 14.1 & 14.4 & 14.4 & 14.4 \\ 31.1 & 30.7 & 30.4 & 30.0 & 29.6\end{array}$


A comparison of maximum deflections from the whole-span uniformly distributed traffic load $p_{2}$ is shown in Fig. 6. The continuous and discrete nonlinear methods give practically the same maximum vertical deflections which are about $70-80 \%$ of the values obtained with the linear FEM method.

Figure 7 shows that maximum vertical displacement, in case of double axle traffic load, is 1.1 times greater than the value in case of the effective traffic load.

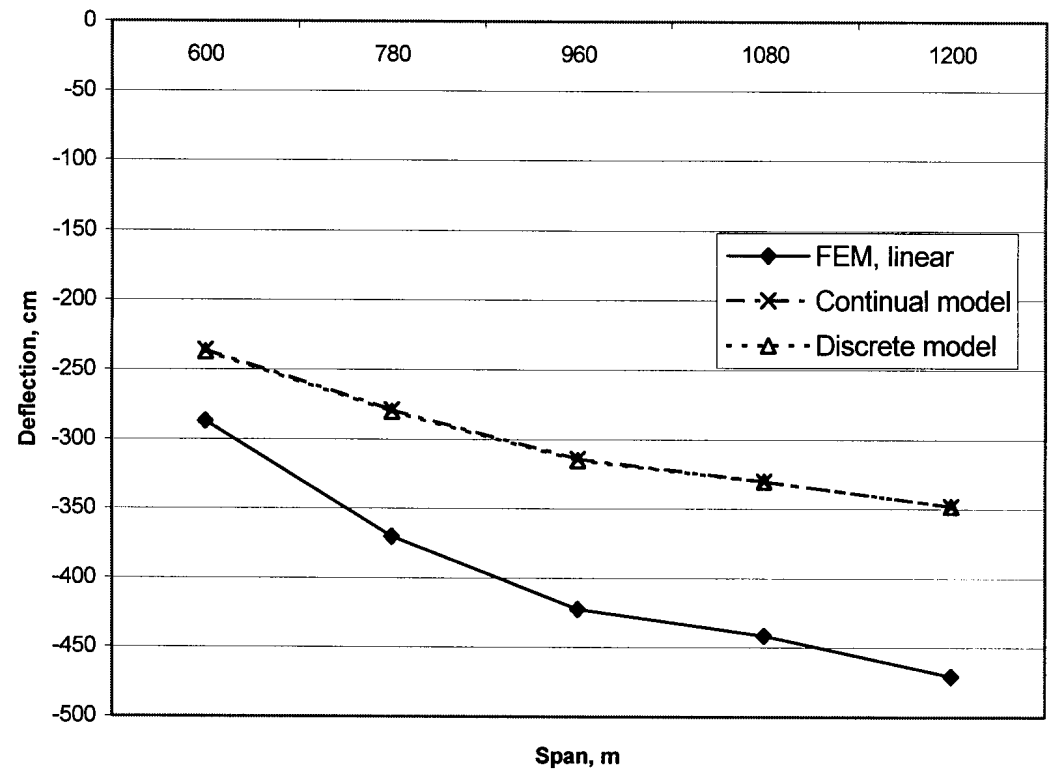

Fig. 6. Maximum deflections from the whole-span uniformly distributed traffic load.

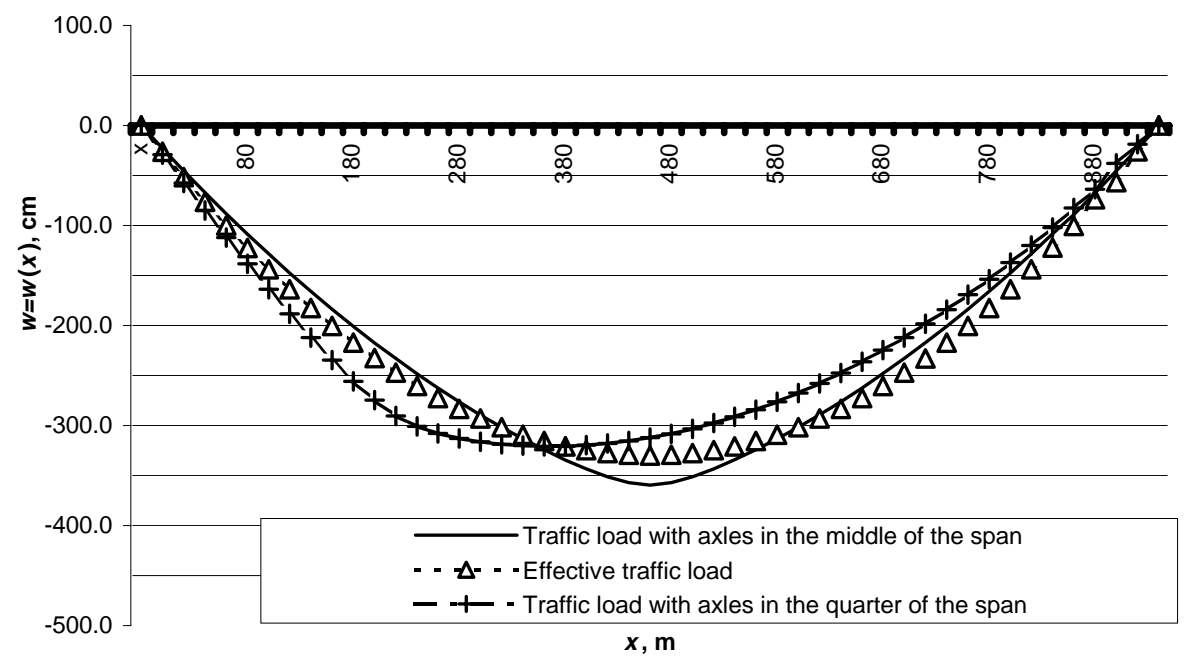

Fig. 7. Deflections from the whole-span load with axles in the middle of the span and at a quarter of it. 
Thus the linear principle of superposition of the load is not valid for suspension bridges. The deflection caused by traffic load is calculated as the difference between the deflection, determined for the total load and that calculated for the dead load only:

$$
w\left(p_{2}\right)=w\left(p_{1}+p_{2}\right)-w\left(p_{1}\right) .
$$

\section{CONCLUSIONS}

The geometrically non-linear equations for discrete and continuous modelling of suspension bridges presented in this paper permit adequate determination of deflections and inner forces of girder-stiffened cable structures. Continuous model may be preferred in case of uniformly distributed loads. More exact analysis of bridges under action of great concentrated loads requires application of the system of equations of the discrete calculation model. Numerical examples demonstrate a good accordance between results of the discrete and continuous methods. Comparison of the results with those obtained with the usual FEM approach shows that in the latter case the deflections exceed those obtained with the non-linear analysis about 1.3-1.4 times.

\section{REFERENCES}

1. Smirnov, V. A. Long-Span Suspension Bridges. Vysshaya shkola, Moscow, 1975 (in Russian).

2. Gimsing, N. J. Cable Supported Bridges. J. Wiley, New York, 1983.

3. Aare, J. and Kulbach, V. Accurate and approximate analysis of statical behaviour of suspension bridges. J. Struct. Mech., 1984, 17, 1-12.

4. Kulbach, V. and Õiger, K. Static Analysis of Suspended Systems. Tallinn Polytechnical Institute, Tallinn, 1986 (in Russian).

5. Kulbach, V. Statical analysis of girder- or cable-stiffened suspended structures. Proc. Estonian Acad. Sci. Eng., 1995, 1, 2-19.

6. Cable Supported Bridges - Challenging Technical Limit. IABSE Reports, vol. 84, 2001.

7. Bangash, M. Y. H. Suspension and Cable-Stayed Bridges. Prototype Bridge Structures. Thomas Telford Publishing, London, 1999.

8. Jörgensen, G. R., Petersen, A., and Pettersson, L. Höga Kusten bridge, Sweden. Struct. Eng. Internat., 1999, 9, 106-108.

9. Cho, C.-Y., Lee, S.-W., and Park, S.-Y. Yongjong self-anchored suspension bridge. Struct. Eng. Internat., 2001, 11, 21-23. 


\title{
Rippsilla diskreetne ja pidev modelleerimine
}

\author{
Valdek Kulbach, Siim Idnurm ja Juhan Idnurm
}

Artiklis on vaadeldud rippsilla arvutamist nii diskreetse kui ka pideva mudeli abil. Diskreetsel mudelil põhinevat metoodikat on seni üldjuhul kasutatud ainult sadulakujuliste eelpingestatud rippkatuste arvutamisel. Siinne töö näitab võimalusi rippsildade arvutamiseks diskreetse mudeli alusel. Vastava võrrandisüsteemi koostamisel lähtuti geomeetriliselt mittelineaarsetest tasakaalutingimustest ja üldistatud geomeetrilise vastavuse võrranditest, millesse on sisse viidud tugede siirded ankurvantide deformatsioonide toimel. Diskreetse mudeli rakendamine võimaldab täpsustada pideva mudeli arvutustulemusi lisaks hajukoormusele ka sõidukitelt üleantavate koondatud koormuste mõjumisel. Nii pidevat kui ka diskreetset arvutusmudelit kasutati Saaremaa püsiühenduse raames kavandatava rippsilla esialgsete projektlahenduste väljatöötamisel. 